\title{
LOS LAZOS DÉBILES: UNA PUERTA A LA INNOVACIÓN
}

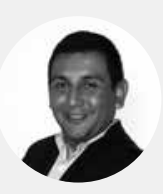

\author{
JOSÉ L. MATOS
}

- Gerente General de Jose Matos Consultores

\section{RESUMEN}

La red de contactos se ha convertido en un importante instrumento social generador de oportunidades laborales y empresariales. Pero ¿qué son estas redes? ¿Cómo se componen? Estas preguntas son importantes porque las relaciones socio-laborales representarían un factor clave para el progreso personal en materia laboral y para el crecimiento económico. El término "red de contactos" hace referencia a un conjunto de personas con las que uno establece algún tipo de relación social. La literatura indica que las relaciones que se van construyendo a lo largo de la vida se diferencian entre sí por el tipo de lazos que se establece entre las personas. Estos lazos, de acuerdo con el tiempo de la relación, la intensidad, la confianza, la reciprocidad y la frecuencia, pueden clasificarse como "débiles" o "fuertes". En este ensayo se argumenta que, contrariamente a lo que podríamos pensar, son los lazos débiles los que juegan un rol protagónico; y se resalta el papel positivo de estos lazos sobre muchos aspectos, subrayándose las oportunidades de empleo, la expansión del conocimiento y el proceso de innovación empresarial.

Palabras clave: networking, red social, capital social. Education plays a fundamental role in the political,

\section{ABSTRACT}

The network of contacts has become an important social instrument for generating labor employment and business opportunities. But what are these networks? How are they formed? These questions are important because social and labor relations tend to be key factors in both personal progress in labor matters and economic growth. "Network of contacts", as a term, refers to a set of people with whom some type of relationship is established. The literature shows that the relationships that are built throughout life are differentiated by the type of ties that are established between people. These ties, according to the length of the relationship, its intensity, and trust, reciprocity, and frequency, can be classified as "weak" or as "strong." In this essay, it is argued that, contrary to what we might think, it is the weak ties that play a leading role, when it comes to progress and growth; it highlights the positive role of these ties on many aspects, of which employment opportunities, the expansion of knowledge, and the process of business innovation are singled out.

Keywords: networking, social network, social capital

El sociólogo estadounidense y profesor de Johns Hopkins University, Mark Granovetter publicó un estudio de muestra aleatoria en 1973, titulado The Strength of Weak Ties. En su investigación se menciona que se entrevistó a un número de empleados de nivel ejecutivo en un suburbio de Boston para saber cómo habían obtenido su trabajo más reciente. Se contemplaron tres opciones con las que responder: contactos personales, avisos en el periódico y la agencia de empleos. De los que respondieron que a través de contactos personales obtuvo una muestra aleatoria ( $N=54$ ). Empleando una escala de frecuencia de interacción, Granovetter (1973) clasificó los lazos de cada entrevistado con su respectivo contacto de trabajo en dos categorías -fuerte y débil-, según las cinco propiedades siguientes:

1. El tiempo de existencia de la relación;

2. La intensidad emocional de la misma;

3. El grado de confianza o de intimidad;

4. La reciprocidad de favores;

5. La frecuencia de interacción.

El 55.6\% de los individuos de la muestra indicó tener una relación débil con su contacto laboral, mientras que el 27.8\% recurrió al amigo de un amigo. Finalmente, el 16.7\% declaró tener una relación cercana, de parentesco o de amistad, con su contacto. La fuerza de los lazos débiles se convirtió desde entonces en un ícono del análisis de redes sociales; Granovetter, el 'gurú' de este enfoque, y su estudio fue replicado en varias ciudades del mundo con resultados similares. (Alcántara Valverde, 2006). Puntualmente, cuando se trata de encontrar trabajo los individuos lo hacen preferentemente a través de lazos débiles.

¿Cómo explicar la aparente incongruencia sociológica de dicha conclusión? Si en principio la familia y el círculo de íntimos constituyen la plataforma utilitaria y emocional de todo individuo ¿cómo es que para algo tan 
fundamental como el empleo los individuos prefieran obtenerlo a través de desconocidos? Pues bien, más adelante, Degenne, Fournier, Marry y Mounier (1991), confirmaron los resultados de Granovetter, al replicar su estudio con una muestra de ejecutivos franceses en los suburbios de París. Estos autores encontraron que los individuos tendían a recurrir a sus lazos fuertes (e.g., familiares y amigos íntimos) en momentos de crisis económica. Asimismo, notaron que para acceder a los altos puestos de las empresas privadas, los lazos fuertes son casi siempre indispensables.

\section{APROXIMACIÓN TEÓRICA}

La fuerza de los lazos es una de las características más frecuentemente observadas en los análisis de redes y particularmente al estudiar redes personales. Si bien su uso precede a la propuesta de Granovetter sobre la fuerza de los lazos débiles (1973), el interés sobre la medida creció significativamente a partir de esta idea, y su desarrollo conceptual es deudor en gran parte de su planteamiento original. Resumidamente, la tesis sobre la fuerza de los lazos débiles sugiere que este tipo de contactos suponen una buena aproximación a los bridges o puentes en una red, ya que las personas con quienes tenemos una relación menos cercana suelen pertenecer a círculos socialmente distintos de los que frecuentamos en nuestras relaciones cotidianas y, consecuentemente, disponen de informaciones distintas y nuevas en relación con las que maneja nuestro entorno. Esto último puede suponer una ventaja comparativa. En la teoría de redes sociales, un puente es un vínculo que une dos partes de una red, que de otro modo serían componentes diferenciados. Es decir, es el único vínculo entre los dos sectores. Un puente local, estrictamente, es el camino más corto entre dos sectores de una red unidos en algún otro punto (véase la figura 1), sin ningún vecino en común entre los extremos del puente, como el caso de los nodos A y B. (Cruz Gómez \& Verd, 2013).

\section{Fig. 1. Puentes locales}

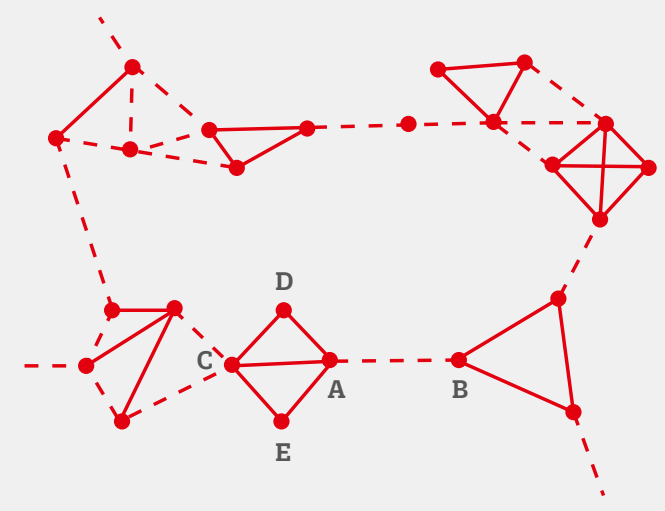

Fuente: Granovetter, 1973, p. 1365.
Peter Marsden y Karen Campbell, en su artículo Measuring Tie Strength (1984), son los autores que con mayor detalle han analizado las dificultades que supone la medición de la fuerza de los vínculos, fruto, tanto del carácter multidimensional de la definición que ofrece Granovetter, como de sus dificultades de operativización. Estas dificultades han dado pie al uso de una gran diversidad de indicadores en la literatura académica, relativos, tanto a características del ego, como a la red social o a la relación entre los nodos.

Marsden y Campbell (1984) se formulaban la pregunta sobre cuál es la mejor medida de la fuerza de los lazos. Para contestarla, se plantearon el ejercicio de "construir y validar" distintas medidas de la fuerza del vínculo, empleando fundamentalmente los indicadores originalmente sugeridos por Granovetter, es decir, la cantidad de tiempo, la intensidad emocional, la confianza mutua y los servicios recíprocos. También se valieron de otras medidas habitualmente empleadas hasta ese momento en la literatura, que en el fondo son pequeñas adaptaciones de los indicadores originales: amplitud de las temáticas discutidas, homofilia/distancia social, tiempo de conocimiento y frecuencia de contacto. Sin embargo, hay que tener en cuenta que Marsden y Campbell emplearon datos sobre los tres mejores amigos de las personas encuestadas; es decir, sólo trabajaron con información de lazos fuertes. Entre sus conclusiones destacan: a) la disfunción entre lo que son propiamente indicadores de la medida, parte constitutiva de la fuerza del vínculo, como por ejemplo, la intensidad emocional y lo que denominan "predictores", aspectos relacionados pero no constitutivos de la fuerza del lazo, como por ejemplo, si la relación que une a dos nodos es de parentesco, amistad, conocimiento, etcétera; b) la afirmación de que el indicador sobre la cercanía afectiva o la intensidad emocional es la mejor medida entre todas las contrastadas; y finalmente, c) que los predictores, como por ejemplo el tipo de relación entre los nodos, no son buenas medidas del fenómeno. Por otro lado, Marsden y Campbell proponen diferenciar "dos aspectos" distintos en las características de la definición ofrecida por Granovetter. El primero, un aspecto relacionado con el tiempo invertido en la relación; y un segundo aspecto que tendría que ver con la profundidad de la relación. Es decir, se podría considerar como próxima, tanto la relación con una persona con la que se pasa mucho tiempo en común, como con la que se comparte mucha confianza y/o intensidad afectiva. De modo inverso, se podría considerar como un lazo débil tanto a una persona con la que tenemos un contacto muy esporádico, como una con la que mantenemos una relación muy superficial.

Partiendo de estas ideas iniciales de Marsden y Campbell, junto con las reflexiones provenientes de otros autores ensayamos a continuación una clasificación teórica de las posibles dimensiones a las que hace referencia la noción de "fuerza de un lazo". La clasificación que presentamos distingue tres grandes dimensiones en el concepto, a las que hemos llamado dimensión "expresiva", dimensión "estructural" y dimensión "social". Además, se proponen tres sub-dimensiones de la dimensión expresiva. 
A pesar del gran número de referencias en la literatura a la fuerza de los vínculos, son escasos los trabajos que han intentado identificar las distintas dimensiones del concepto. En nuestro caso, la clasificación que proponemos es el resultado de la revisión de numerosos artículos que han trabajado teórica y/o empíricamente la noción de fortaleza de los lazos, entre los cuales destacan las obras clásicas de Granovetter (1973), Friedkin (1980) y Lin, Ensel y Vaughn (1981).

En el ámbito empresarial, el profesor Gautam Ahuja de la Universidad de Chicago, en su artículo Collaboration Networks Structural Holes and Innovation: A Longitudinal Study, publicado en 1998, realiza un análisis a las empresas de la industria química en los Estados Unidos bajo tres aspectos: lazos fuertes, lazos débiles y lazos vacíos entre socios. Analizando las patentes anuales, datos de colaboración, atributos y datos de las empresas, la investigación arrojó, a modo de conclusión, que a diferencia de los lazos fuertes y lazos vacíos, es en la gestión de los lazos indirectos de manera eficiente y efectiva que se logra maximizar los beneficios de las redes. Los lazos indirectos sirven como un mecanismo de expandir el conocimiento y contribuye de manera positiva a la producción de la innovación. Borges Jr. (2004) hace suyas las definiciones de Granovetter para enfatizar el papel que estos lazos tienen en el proceso de innovación tecnológica. Así, considera a los lazos débiles como más propicios para que el cambio ocurra, una vez que hacen que los individuos perciban otras realidades. La dimensión relacional, focaliza el rol de los lazos directos entre los actores en relación con los contenidos de las transacciones, según Nahapiet y Ghoshal (1998), en las interacciones y su diversidad. Entre los contenidos de las transacciones en esta dimensión están: la amistad, el intercambio de informaciones, el respeto, la confianza, las normas, las sanciones o el consejo y la identificación.

La primera técnica aplicada por Toyota y que está completamente implantada en ZARA fue el "Sistema Pull”, que se lleva a cabo a través de tarjetas “Kanban”. El sistema utiliza un ajustado stock intermedio de materiales (semiterminados) que están listos para ser usados por el siguiente proceso en el momento que lo necesita. Cuando se usa un material, se envía una señal al anterior proceso para reemplazar lo que se ha utilizado o se ha completado. Así, desde que el cliente compra, que es el último proceso, hasta el comienzo de la fabricación, que es el primero, sin tener en cuenta proveedores. Para evitar el exceso en la producción, el sistema mantiene pequeñas cantidades de materiales semiterminados que se necesitan y reemplazan tan sólo lo que se utiliza, sólo cuando se ha utilizado.

Para alimentar este sistema, ZARA utiliza una red de fábricas automatizadas en España y más de 300 pequeñas fábricas de acabado en el norte de África y Turquía, creando constantemente materiales semiterminados. Cuando un diseño es aprobado, los materiales semiterminados necesarios son enviados a las fábricas de acabado para su transformación en producto final, listos para ser enviados en tan sólo 24 horas para Europa y en 40 horas a los mercados de Asia y América del Norte. El resto de materiales semiterminados se pierde, pero siempre será de mucho menor importancia que el producto ya finalizado.

Este sistema produce por tanto pequeñas cantidades para adaptar la oferta a la demanda de los clientes, al contrario de producir grandes cantidades de productos estandarizados, que provocan excesos de stocks y posibles pérdidas por baja demanda. Con el flujo de pocas cantidades de producción, se responde además a la demanda de forma más rápida y eficiente.

El resultado es que aproximadamente ocho horas después de que el gerente de tienda hace el pedido en base a la demanda, los artículos son recogidos, embalados y listos para salir de su centro de distribución en el noroeste de España para cualquier lugar del mundo (Gómez García, 2016).

Zara obtiene el 85\% del precio de lista mientras que el promedio del sector está en el orden del 60 y 70\%; y recibe un margen neto sobre las ventas de $10,5 \%$ mayor a sus rivales.

La "magia" reside en que Zara aplica sistemas Just in time - JIT - que fueron desarrollados junto a Toyota, lo que hace que mantenga casi el 50\% de la producción in house. No persigue economías de escala sino que fabrica y distribuye en pequeñas cantidades y no se apoya en socios externos sino que maneja por cuenta propia todas sus operaciones de diseño, almacenamiento, distribución y logística.

Esto contrasta con el modelo de muchos fabricantes de indumentaria que tercerizan toda su producción y algunos de sus procesos más críticos; fabrican y distribuyen lotes enormes, se quedan con remanentes de temporadas que llenan varias estanterías de depósitos y que muchas veces deben liquidar para poder obtener un margen escaso (Briasco, 2009).

Otro caso famoso de innovación por medio de los lazos débiles, se dio en la empresa Procter \& Gamble (P\&G) para el producto Pringles, en donde un empleado sugirió la idea de imprimir mediante inyección de tinta sobre la masa de las hojuelas, imágenes, preguntas de cultura general, chistes o datos sobre animales. $\mathrm{P} \& \mathrm{G}$ se dio cuenta de que cada papa debía ser impresa al salir del proceso de fritura, cuando todavía tenía un alto grado de humedad y temperatura. Además que las imágenes deberían ser nítidas en múltiples colores e imprimir miles de papas fritas por minuto, se requería crear una tinta comestible. Hacer este proceso de innovación ella misma, según sus estimaciones, le hubiera demorado más de 2 años, al no tener experiencia en la materia. Así que sus empleados optaron por averiguar a través de sus redes globales de personas e instituciones si alguien en el mundo ya tendría una solución a este problema. Fue así que llegaron hasta una pequeña panadería en Bologna, Italia, la cual era dirigida por un profesor universitario que había inventado un método de inyección de tinta para imprimir imágenes comestibles en bizcochos y galletas. P\&G adaptó rápidamente esta tecnología para resolver su problema. Esta innovación sirvió para que el negocio de Pringles de P\&G América del Norte alcanzara un crecimiento de dos dígitos (Huston \& Sakkab, 2006). 
Mirar siempre nuestros lazos débiles nos lleva a tener acceso a un mayor conocimiento y tomar dicho conocimiento para innovar nuestros procesos y por lo tanto ser más competitivos. No dejemos de ver esos lazos débiles en nuestro alrededor, evitando así que otro más lo haga y nos saque ventaja.

\section{REFERENCIAS}

Ahuja, G. (2000). Collaboration networks, structural holes and innovation: A longitudinal study. Academy of Management Proceedings, 45(3), 425-455. doi:10.2307/2667105

Alcántara Valverde, N. (2006). Lazos debiles en el medio politico. El Cotidiano, 21(138), 79-87. Obtenido de https://www.redalyc.org/html/325/32513808/

Borges Jr., C. V. (2004). Características e contribuições das redes para o desenvolvimento das pequenas e médias empresas. Anais $28^{\circ}$ Encontro da Associação Nacional de Pós-Graduação em Administração, Brasil. Obtenido de http://www.anpad.org.br/raccopy/IBHGSKYAAJ.doc

Briasco, G. (28 de Noviembre de 2009). Lean management, de Toyota a Zara. MATERIABIZ Escuela de Negocios. Obtenido de https://materiabiz.com/leanmanagement-de-toyota-a-zara/

Cruz Gómez, I., \& Verd, J. M. (2013). La fuerza de los lazos: Una exploración teórica empírica de sus múltiples significados. Empiria. Revista de Metodología de Ciencias Sociales, O(26), 149-174. doi:10.5944/ empiria.26.2013.7156

Degenne, A., Fournier , I., Marry, C., \& Mounier, L. (1991). Les relations au cœur du marché du travail. Sociétés Contemporaines, 5, 75-97. doi:10.3406/socco.1991.988

Friedkin, N. (1980). A test of structural features of Granovetter's strength of weak ties theory. Social Networks, 2(4), 411-422. doi:10.1016/03788733(80)90006-4

Gómez García, E. -A. (26 de Julio de 2016). Cómo el “Sistema Pull", como parte de "Lean" ha ayudado a ZARA [Web log post]. Obtenido de http://www.eoi.es/blogs/ emiliogomez/2016/07/26/como-el-sistema-pull-comoparte-de-lean-ha-ayudado-a-zara/

Granovetter, M. S. (1973). The strength of weak ties. American Journal of Sociology, 78(6), 1360 - 1380. Obtenido de https://sociology.stanford.edu/sites/ default/files/publications/the_strength_of_weak_ties_ and_exch_w-gans.pdf

Huston, L., \& Sakkab, N. (2006). Conectar y desarrollar dentro del nuevo modelo de innovación de Procter \& Gamble. Harvard Business Review, 84(3), 54-65. Obtenido de https://dialnet.unirioja.es/servlet/ articulo?codigo=1710386
Lin, N., Ensel, W. M., \& Vaughn, J. C. (1981). Social resources and strength of ties: structural factors in occupational status attainment. American Sociological Review, 46(4), 393-405. doi:10.2307/2095260

Lubbers, M., \& Molina, J. L. (2013). El proceso de la reconstrucción de la red personal de los inmigrantes: Una descripción longitudinal. Empiria. Revista de Metodología de Ciencias Sociales, O(26), 63-88. doi:10.5944/empiria.26.2013.7153

Marsden, P. V., \& Campbell, K. E. (1984). Measuring tie strength. Social Forces, 63(2), 482-501. doi:10.2307/2579058

Nahapiet, J., \& Ghoshal, S. (1998). Social capital, intellectual capital, and the organizational advantage. The Academy of Management Review, 23(2), 242-266. Obtenido de https://papers.ssrn.com/sol3/papers. cfm?abstract_id=1505219 